\title{
Nanofosil Gampingan Formasi Ofu Berumur Neogen di Pulau Rote
}

\author{
Angga Jati Widiatama ${ }^{1 *}$, Lauti Dwita Santy ${ }^{2}$, Rikza Nur Faqih An Nahar ${ }^{1}$, Adrianus Damanik ${ }^{3}$, Winda \\ Eka Mandiri Puteri ${ }^{3}$, Zulfiah ${ }^{3}$ \\ ${ }^{1}$ Program Studi Teknik Geologi, Institut Teknologi Sumatera \\ ${ }^{2}$ Pusat Survei Geologi, Badan Geologi, Kementrian Energi dan Sumber Daya Mineral \\ ${ }^{3}$ Teknik Geologi, Institut Teknologi Bandung
}

\begin{abstract}
Abstrak
Formasi Ofu merupakan bagian paling muda dari sikuen Kolbano yang litologinya didominasi batugamping pelagik. Belum adanya penelitian tentang diversitas dan zonasi umur nanofosil gampingan menjadikan riset ini penting dilakukan. Riset ini berhasil mengidentifikasi tujuh famili dan 19 spesies nanofosil gampingan. Nanofosil gampingan didominasi genus Discoaster, Dictyococcites, dan Reticulofenestra yang dapat dibagi menjadi tiga zonasi, dan satu zona transisi Pliosen-Pleistosen. Permulaan Miosen, Burdigalian-Tortonian (zona NN 2-NN 10) ditandai pemunculan awal Helicosphaera kamptneri hingga pemunculan awal Discoaster quinqueramus. Zona NN11 yang berumur Tortonian-Messinian ditandai pemunculan awal hingga pemunculan akhir Discoaster quinqueramus. Zona NN12-NN15 (Messinian-Zanclean) ditandai pemunculan awal hingga pemunculan akhir Discoaster pansus. Transisi Pliosen-Pleistosen (NN 16-NN 21) ditandai dengan pemunculan akhir dari Discoaster pansus hingga pemunculan akhir Dictyococcites productus dan Helicosphaera princei. Tingginya diversitas nanofosil mengindikasikan kondisi upwelling. Melimpahnya genus Helicosphaera serta genus Calcidiscus merupakan indikasi daerah upwelling yang dipengaruhi oleh pertemuan arus hangat dan arus dingin.
\end{abstract}

Kata kunci: Nanofosil gampingan; Neogen; Pulau Rote.

\begin{abstract}
The Ofu Formation is the youngest part of the Kolbano sequence whose dominated by pelagic limestones. There is no research has been carried out on diversity and calcareous nannofossils age zonation makes this research important. This research has identified seven families and 19 calcareous nannofossils species. Limestone nannofossils are dominated by the Discoaster, Dictyococcites, and Reticulofenestra genera that can be divided into three zones, and one Pliocene-Pleistocene transition zone. The Early Miosen as Burdigalian-Tortonian (NN 2-NN 10 zone) characterized by the first occurance of the Helicosphaera kamptneri to the first occurance of Discoaster quinqueramus. The NN 11 zone (Tortonian-Messinian) marked by first occurance until the last occurance of Discoaster quinqueramus. The NN 12-NN 15 zone (Messinian-Zanclean) marked by first occurance until the last occurance of the Discoaster pansus. The Pliocene-Pleistocene transition (NN 16-NN 21) characterized by the last occurance of the Discoaster pansus to last occurance of Dictyococcites productus and Helicosphaera princei. The high diversity of nannofossils indicates upwelling conditions. Abundance of Helicosphaera genus and Calcidiscus genus interpreted as an upwelling area influenced by warm and cold currents confluence.
\end{abstract}

Keywords: Calcareous nannofossil; Neogen; Rote Island.

\footnotetext{
*) Korespondensi : anggajatiwidiatama@gmail.com

Diajukan : 11 April 2021

Diterima : 21 Juli 2021

Diterbitkan : 3 Desember 2021
} 


\section{PENDAHULUAN}

Pulau Rote, Pulau Timor, dan beberapa pulau kecil lain di sekitarnya merupakan pulau yang terbentuk dari akresi endapan tepi Benua Australia (Audley-Charles, 2011; Villeneuve dkk., 2013). Beberapa peneliti telah melakukan penelitian sedimentologi dan peleontologi Busur Banda, membagi lima kelompok litotektonik antara lain; (1) Sikuen Gondwana berumur Permian hingga Jura yang berisi batuan silisiklastik yang terendapkan pada cekungan intrakraton, (2) Sikuen Kolbano berisi batuan silisiklastik dan karbonat pelagik berumur Jura Akhir hingga Neogen, (3) Sikuen Banda terrain yang merupakan bagian dari Asia yang mengalami pengangkatan akibat kolisi selama Neogen Akhir, (4) Bancuh Bobonaro berisi batuan bancuh dengan blok didalam lempung, broken formation, dan kubah lumpur yang terbentuk selama kolisi Neogen akhir, (5) Sikuen Viqueque yang merupakan endapan synorogenik yang relatif tidak terdeformasi (Sawyer dkk., 1993; Audley-Charles, 2011).

Penelitian ini dilakukan pada Formasi Ofu, yang memiliki lokasi tipe di Pulau Timor (Rosidi dkk., 1979; 1996). Litologi tipe Formasi Ofu berupa batugamping masif berwarna putih hingga merah muda yang menunjukkan rekahan konkoidal hingga subkonkoidal dan terlihat mengkilap seperti porselen pada permukaan yang segar. Dalam singkapan terdapat laminasi dan belahan dari pressure solutions yang intensif yang mengakibatkan timbulnya urat-urat kalsit pada stilolit, kekar, dan rekahan lainnya. Sawyer dkk. (1993) membagi menjadi tiga unit yang terpetakan, yaitu Anggota Boti, Borolalu dan Oeleu. Litologinya terdiri atas wackestone pelecypoda dan foraminifera, packstone dengan kuarsa atau packstone foraminifera, dan konglomerat turbidit berlapis dengan fragmen menyudut. Umur unit ini berkisar pada fasa Lutetian pada Eosen Tengah hingga Awal Pliosen.

Formasi Ofu di Pulau Rote (Gambar 1) terdiri dari perlapisan grainstone foraminifera pada bagian bawah yang berangsur menjadi kalsilutit. Formasi Ofu tersingkap baik pada bagian utara dan selatan Pulau Rote bersama dengan satuan Koral terangkat berumur Kuarter (Roosmawati dan Harris, 2009), meskipun Rosidi dkk. (1979; 1996) menyatakan bahwa Formasi Ofu di Pulau Rote berupa bongkah yang tertanam dalam melange Bobonaro.

Penelitian ini bertujuan mengidentifikasi diversitas dan umur relatif nanofosil gampingan pada batuan Formasi Ofu di Pulau Rote yang merupakan bagian dari sikuen passive margin Australia (Kolbano). Belum adanya penelitian penentuan umur dengan menggunakan nanofosil
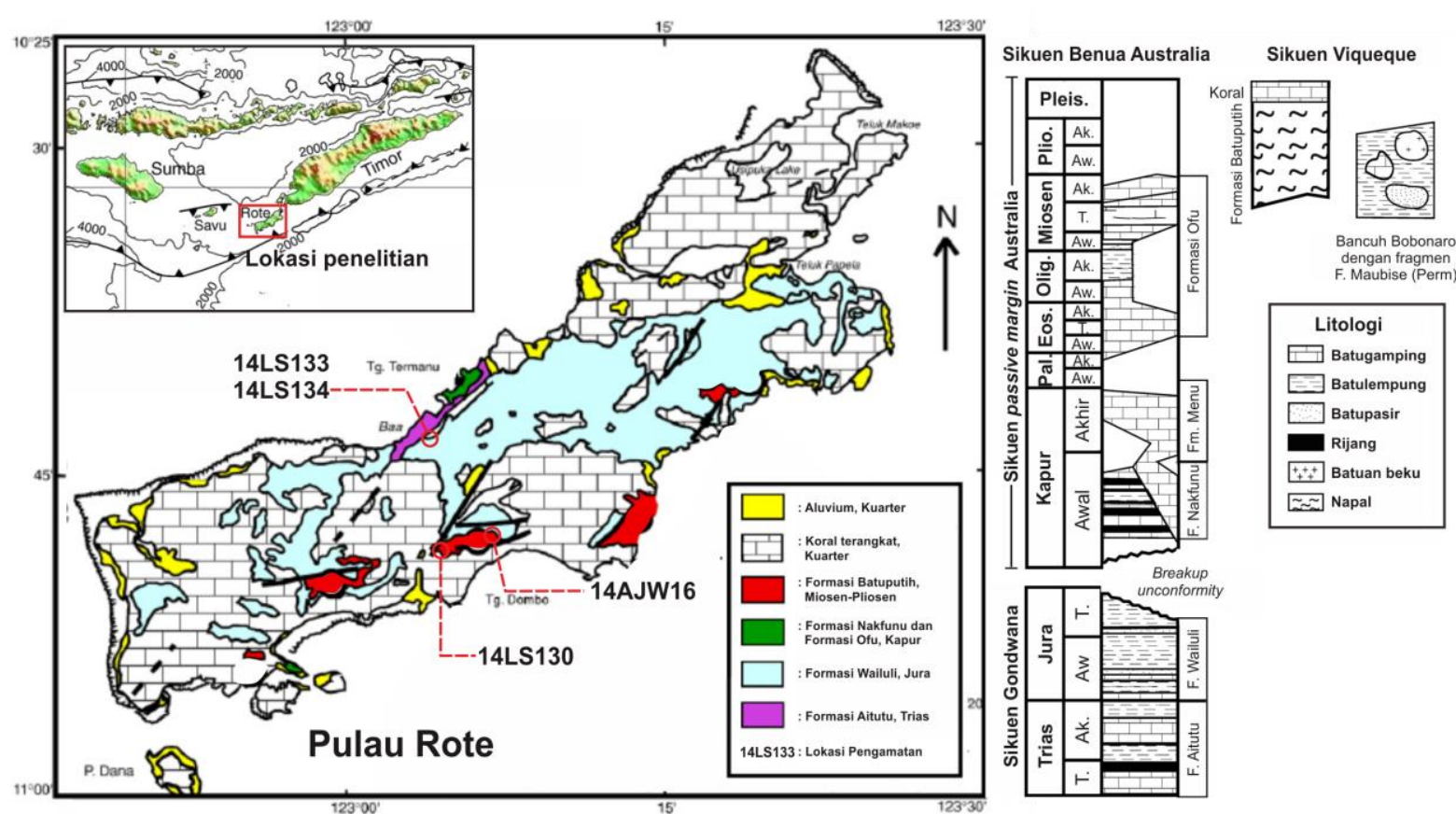

Gambar 1. Peta geologi dan stratigrafi daerah penelitian (Roosmawati dan Harris, 2009) dan lokasi pengamatan penelitian ini. 
gampingan pada Formasi Ofu di Pulau Rote menjadi sebab penelitian ini penting untuk dilaksanakan karena spesies nanofosil penanda memiliki umur relatif yang lebih pendek dibandingkan foraminifera.

\section{METODOLOGI}

Pengambilan data lapangan dilakukan dalam kegiatan survei cekungan Sawu. Penelitian dilaksanakan oleh Pusat Survei Geologi, Badan Geologi, Kementrian ESDM pada tahun 2014. Pengambilan data mencakup pengukuran stratigrafi, deskripsi megaskopis batuan, deskripsi mikroskopis (sayatan tipis), dan paleontologi nanofosil gampingan. Pengamatan dilakukan pada empat titik pengamatan antara lain 14LS130, 14LS133, 14LS134, dan 14AJW16 (Gambar 1). Sebanyak empat sampel nanofosil gampingan dipreparasi dengan metode smear slide atau sayatan oles dengan cara menghancurkan bagian kecil dari batuan di atas kaca preparat lalu ditutup dengan larutan cairan entellan. Pengamatan nanofosil gampingan meggunakan mikroskop polarisasi dengan perbesaran 1000x. Penarikan umur nanofosil gampingan Kenozoikum menggunakan zonasi Martini (1971).

\section{HASIL PENELITIAN}

\section{Zonasi Nanofosil Gampingan}

Secara umum karakter Formasi Ofu di Pulau Rote didominasi oleh grainstone foraminifera. Bagian bawah Formasi Ofu (14LS133 dan 14LS134) terdiri grainstone foraminifera berwarna merah hingga jingga (Gambar 2A dan 2B), berlapis baik, tebal lapisan antara 10-20 $\mathrm{cm}$, kompaksi sedang, dan strukur sedimen laminasi sejajar, terdapat sisipan mudstone dengan struktur fissile. Bagian ini berumur Burdigalian-Tortonian (NN 2-NN 10) ditandai dengan pemunculan awal Helicosphaera kamptneri hingga pemunculan Discoaster quinqueramus. Diatasnya berupa grainstone, berwarna putih, tebal lapisan antara $15-25 \mathrm{~cm}$, dengan komponen bioklas foraminifera planktonik yang dominan (Gambar 2C dan 2D). Pada titik 14LS134 dijumpai Discoaster quinqueramus yang merupakan biota penanda zona NN 11 atau memiliki kisaran umur antara Tortonian-Messinian.

Bagian tengah Formasi Ofu teramati pada lokasi 14LS130 yang memiliki litologi grainstone foraminifera dengan sisipan lapisan packstone tufaan dengan kompaksi sedang, berfragmen piroklastik berupa lapili hingga aglomerat, dan pecahan tumbuhan. Bagian tengah Formasi Ofu berumur MessinianZanclean (NN 12-NN 15) ditandai dengan pemunculan awal Discoaster pansus hingga pemunculan akhir Discoaster pansus.

Bagian atas Formasi Ofu (14AJW16) terdiri dari grainstone foraminifera berlapis buruk dengan kompaksi sedang (Gambar 2E), pada beberapa tempat dijumpai juga lapisan packstone dengan tebal lapisan antara $10-15 \mathrm{~cm}$ (Gambar 2F). Bagian atas Formasi Ofu memiliki umur berkisar NN 16-NN 21 (PlacenzianPleistosen). Bagian ini ditandai dengan pemunculan akhir dari Discoaster pansus hingga pemunculan akhir Dictyococcites productus dan Helicosphaera princei. Gambar biozonasi nanofosil gampingan dan kolom stratigrafi terukur dapat dilihat pada Gambar 3. Sedangkan foto nanofosil terpilih ditampilkan pada Gambar 4.

\section{Diversitas Nanofosil Gampingan}

Nanofosil gampingan di Pulau Rote terdiri dari tujuh famili dan 19 spesies. Famili Discoasteraceae memiliki diversitas spesies paling banyak dengan delapan spesies, Noelaerhabdaceae dengan empat spesies, Helicosphaeraceae dengan dua spesies, Sphenolithaceae dengan dua spesies, Calcidiscaceae dengan satu spesies, Coccolithaceae dengan satu spesies, dan Nannolith families inc. sed. satu spesies. Diversitas spesies dapat dilihat pada Tabel 1.

Keberadaan 19 jenis spesies berbeda menunjukkan relatif tingginya diversitas nanofosil gampingan saat Formasi Ofu terendapkan. Menurut Chira dan Malacu (2008) serta Silva dkk. (2008) tingginya variasi biota pada suatu perairan menunjukkan lingkungan ideal untuk perkembangbiakan nanofosil gampingan akibat adanya upwelling arus laut yang membawa nutrisi yang melimpah.

Upwelling terbentuk oleh beberapa faktor, antara lain posisi lintang, konfigurasi kontinen, dan juga topografi bawah laut (De Wever dkk., 2014). Melimpahnya genus Helicosphaera merupakan karakteristik dari daerah upwelling pada perairan hangat (Perch-Nielsen, 1985; Rahman dan Roth, 1990). Selain itu genus Calcidiscus juga menunjukkan kelimpahan yang relatif tinggi yang mengindikasikan adanya 

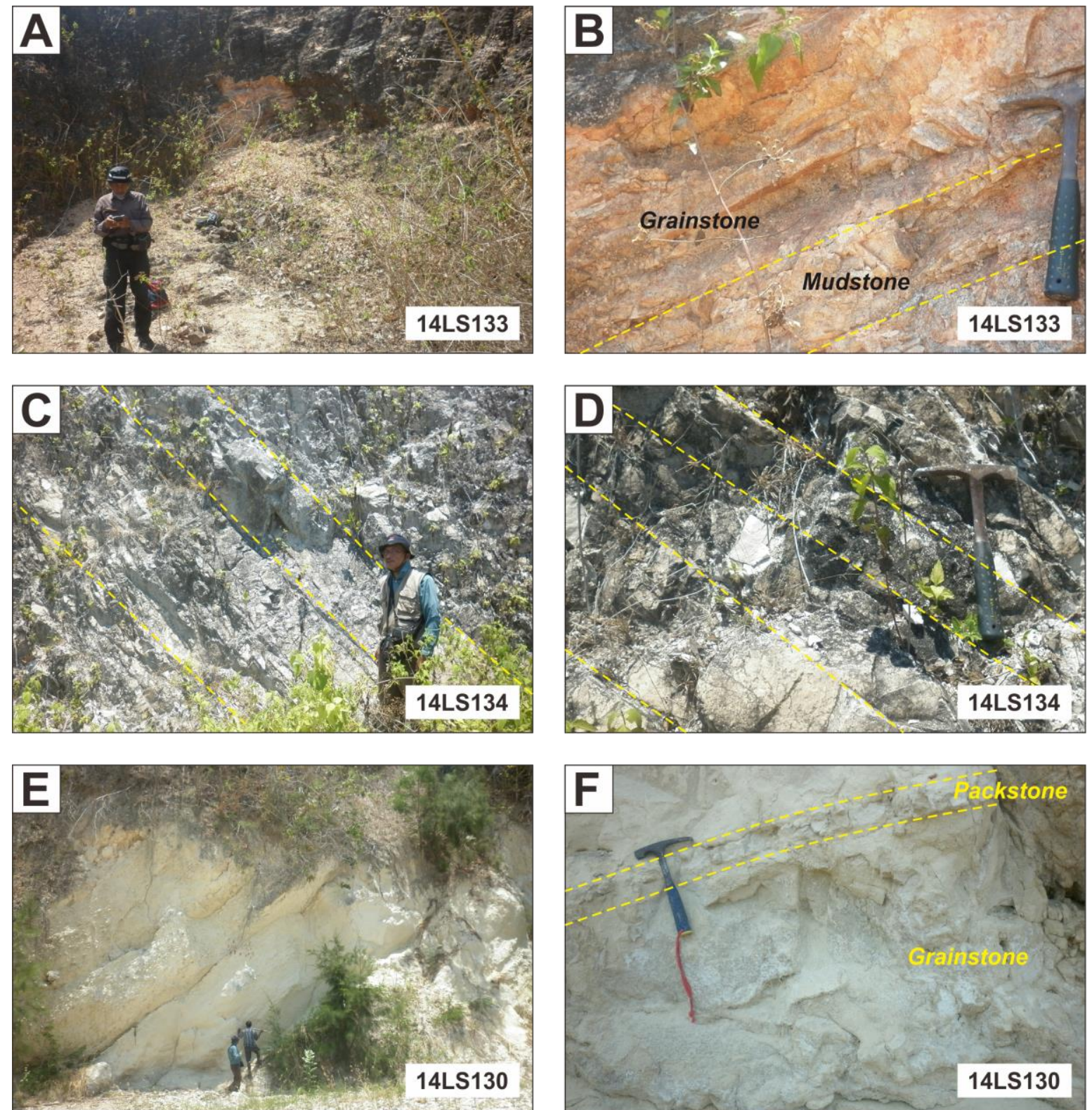

Gambar 2. Foto singkapan Formasi Ofu di Pulau Rote, (A) perlapisan Grainstone, (B) lapisan mudstone dengan tebal lapisan antara 10-20 cm menyisip diantara lapisan grainstone, (C) singkapan perlapisan grainstone foraminifera, (D) grainstone formainifera berlapis, (E) Singkapan bagian atas Formasi Ofu, dan (F) Bagian atas Formasi Ofu berupa grainstone dengan sisipan packstone.

pengaruh arus laut bersuhu dingin pada zona upwelling (Ines, 2017). Hal tersebut mengindikasikan bahwa Pulau Rote pada Miosen hingga Pliosen merupakan zona pertemuan arus hangat dan arus dingin.

Batuan Formasi Ofu bagian bawah menunjukkan fenomena perubahan warna dari merah muda menjadi warna putih (Gambar 2A). Karakter batugamping berwarna merah identik dengan endapan Oceanic Red Bed (ORB) yang tersebar luas yang dikenal sebagai tipe fasies endapan lintang rendah atau laut dengan iklim hangat pada Laut Tethys (Hu dkk., 2005; Wang dkk., 2009; Hu dkk., 2012). Warna merah pada batugamping ditafsirkan akibat adanya unsur besi $\left(\mathrm{Fe}^{2+} / \mathrm{Fe}^{3+}\right)$ yang masuk pada sistem kristal kalsit pada batugamping akibat kondisi lingkungan yang oksik (Cai dkk., 2008; 2009; 2012). 
Tabel 1. Diversitas nanofosil gampingan umur Neogen-Kuarter Pulau Rote

\begin{tabular}{|c|c|c|c|}
\hline No & Nanofosil & No & Nanofosil \\
\hline \multicolumn{2}{|r|}{ Family Discoasteraceae } & & Family Coccolithaceae \\
\hline 1 & Discoaster berggrenii & 12 & Ericsonia cava \\
\hline 2 & Discoaster broweri & \multicolumn{2}{|r|}{ Familiy Noelaerhabdaceae } \\
\hline 3 & Discoaster challengeri & 13 & Dictyococcites productus \\
\hline 4 & Discoaster asymetricus & 14 & Dictyococcites antarcticus \\
\hline 5 & Discoaster quinqueramus & 15 & Reticulofenestra pseudoumbilicus \\
\hline 6 & Discoaster variabilis & 16 & Reticulofenestra minuta \\
\hline 7 & Discoaster pentaradiatus & \multicolumn{2}{|r|}{ Nannolith families inc sed } \\
\hline \multirow[t]{2}{*}{8} & Discoaster pansus & 17 & Florisphaera profunda \\
\hline & Familiy Sphenolithaceae & \multicolumn{2}{|r|}{ Family Helicosphaeraceae } \\
\hline 9 & Sphenolithus abies & 18 & Helicosphaera kamptneri \\
\hline 10 & Sphenolithus neoabies & 19 & Helicosphaera princei \\
\hline \multicolumn{2}{|r|}{ Family Calcidiscaceae } & & \\
\hline 11 & Calcidiscus leptoporus & & \\
\hline
\end{tabular}

Tabel 2. Distribusi semi-kualitatif nanofosil Pulau Rote

\begin{tabular}{|c|c|c|c|c|c|c|c|c|c|c|c|c|c|c|c|c|c|c|c|c|}
\hline Sampel & Biomarker & 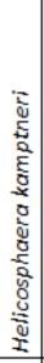 &  &  & 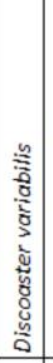 &  & 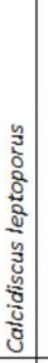 &  & 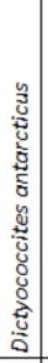 & 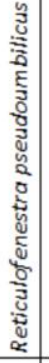 &  & 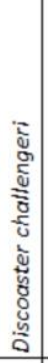 & 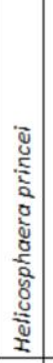 & 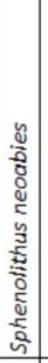 & $\begin{array}{l}8 \\
8 \\
5 \\
5 \\
5 \\
2 \\
0 \\
0 \\
0 \\
0 \\
5 \\
\frac{2}{2} \\
\frac{5}{2} \\
0 \\
0\end{array}$ & 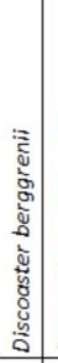 & 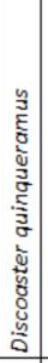 &  &  &  \\
\hline 14AJW16 & \multirow{4}{*}{$\begin{array}{r}\text { H. princei, Dictyocococites productus } \downarrow \\
\text { Discoaster pansus } \downarrow \\
\text { Discoaster pansus } \downarrow \\
\text { Discoaster quinqueramus } \longleftarrow\end{array}$} & III & II & 1 & II & II & II & 1 & & & & II & IV & & & & & & & 1 \\
\hline $14 L S 130$ & & III & III & II & II & II & 1 & I & 1 & & & III & III & 1 & 1 & & & 1 & 1 & 1 \\
\hline 14LS134 & & III & IV & 1 & II & 1 & II & II & 1 & II & II & II & III & 1 & 1 & II & IV & & & \\
\hline 14 LS133 & & 1 & II & 1 & 1 & II & 1 & 1 & 1 & III & 1 & & & & & & & & & \\
\hline & sangat sedikit (1-15); । & & & 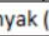 & (15- & 0): & & & & 13 & 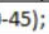 & & & & & & & & & \\
\hline
\end{tabular}

\begin{tabular}{|c|c|c|c|c|c|}
\hline \multicolumn{2}{|c|}{ Umur } & Kolom Stratigr & $\begin{array}{l}\text { Lokasi } \\
\text { Sampel }\end{array}$ & $\begin{array}{c}\text { Zonasi } \\
\text { Nannofosil } \\
\text { (Martini, 1971) }\end{array}$ & $\begin{array}{l}\text { Biomarker } \\
\text { Nannofosil }\end{array}$ \\
\hline \multirow{2}{*}{\multicolumn{2}{|c|}{ Plio.-Pleist. }} & \multirow{7}{*}{  } & \multirow[t]{2}{*}{ 14AJW16 } & \multirow{3}{*}{$\begin{array}{l}\text { NN 21- } \\
\text { NN16 } \\
\text { NN 15- } \\
\text { NN 12 }\end{array}$} & \multirow{3}{*}{$\begin{array}{l}\text { Helicosphaera princei, } \\
\text { Dictyocococites productus } \\
\downarrow \text { Discoaster pansus }\end{array}$} \\
\hline & & & & & \\
\hline Plio. & Me.z. & & $14 L S 130$ & & \\
\hline \multirow{4}{*}{ 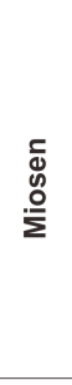 } & 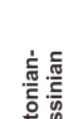 & & & NN 11 & $\rightarrow$ Discoaster quinqueramus \\
\hline & 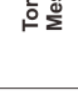 & & 14LS134 & \multirow{3}{*}{$\begin{array}{l}\text { NN 10- } \\
\text { NN } 22\end{array}$} & \\
\hline &  & & & & \\
\hline & レロ & & $14 L S 133$ & & $\uparrow$ Helicosphaera kamptneri \\
\hline
\end{tabular}

Gambar 3. Biostratigrafi nanofosil gampingan Formasi Ofu Pulau Rote. 

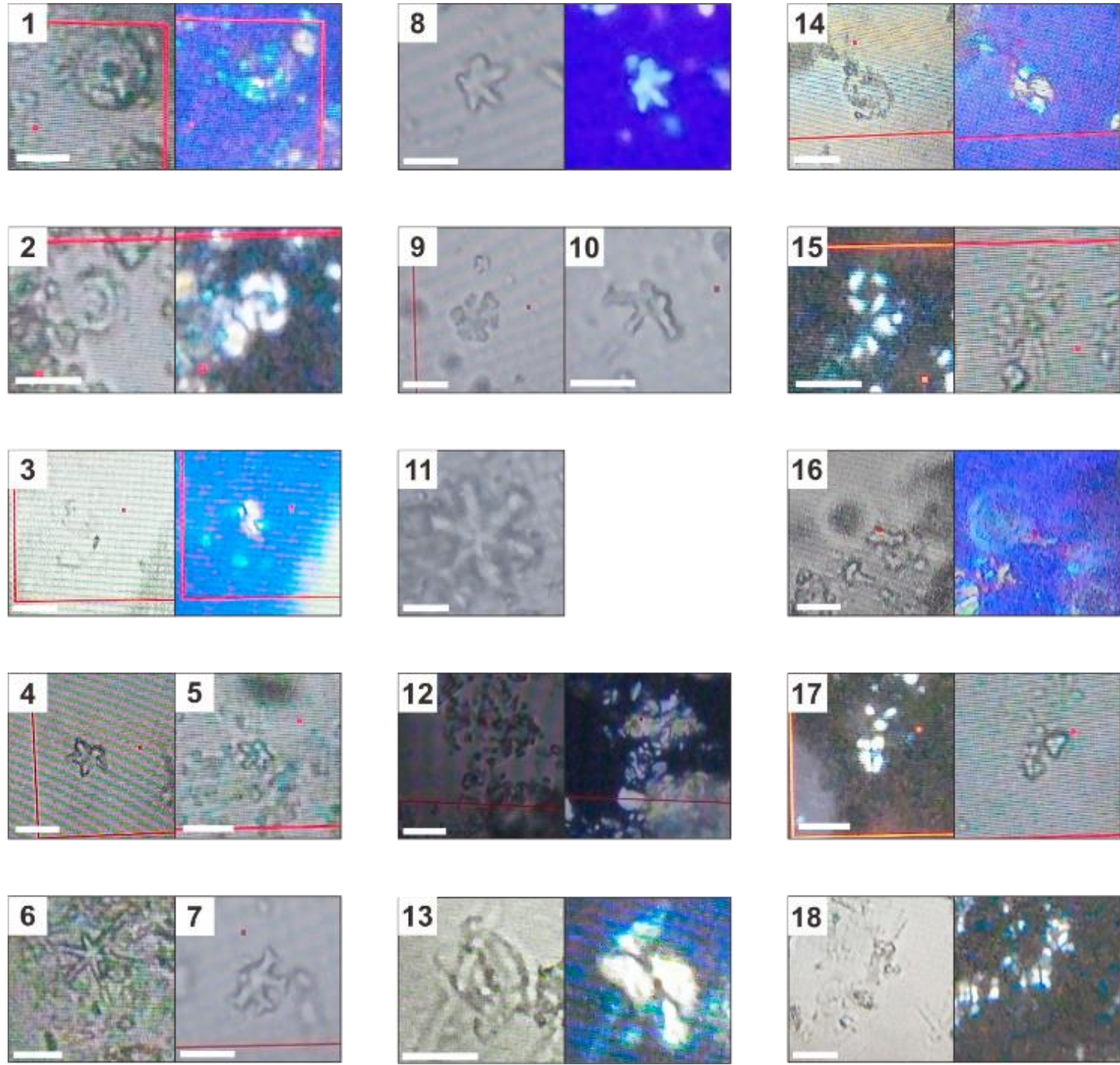

Gambar 4. Foto nanofosil gampingan Formasi Ofu di Pulau Rote. (1) Calcidiscus leptoporus; (2) Dictyococcites antarcticus; (3) Dy. productus; (4) Discoaster berggrenii; (5) D. asymetricus; (6) D. brouweri; (7) D. chalenggeri; (8) D. pentaradiatus; (9) D. pansus; (10) D. quinqueramus; (11) D. variabilis; (12) Florisphaera profunda; (13) Helicosphaera princei; (14) H. kamptneri; (15) Reticulofenestra minuta; (16) $R$. pseudoumbilicus; (17) Sphenolithus abies; (18) S. neoabies. Skala batang $5 \mu \mathrm{m}$.

\section{KESIMPULAN}

Kumpulan nanofosil gampingan di Pulau Rote berumur Neogen terdiri dari tujuh famili dan 19 spesies. Nanofosil gampingan berumur Neogen didominasi genus Discoaster, Dictyococcites, dan Reticulofenestra yang terdiri dari tiga zonasi, dan satu zona transisi Pliosen-Pleistosen. Permulaan Miosen (Burdigalian/zona NN 2-NN 10) ditandai ditandai pemunculan awal Helicosphaera kamptneri hingga pemunculan awal dan Discoaster quinqueramus. Zona NN11 yang berumur Tortonian-Messinian ditandai pemunculan awal hingga pemunculan akhir Discoaster quinqueramus. Zona NN12-NN15
(Messinian-Zanclean) ditandai pemunculan awal hingga pemunculan akhir Discoaster pansus. Transisi Pliosen-Pleistosen (NN 16-NN 21) ditandai dengan pemunculan akhir dari Discoaster pansus hingga pemunculan akhir Dictyococcites productus dan Helicosphaera princei. Tingginya diversitas nanofosil mengindikasikan kondisi upwelling pada lingkungan Formasi Ofu terendapkan. Melimpahnya genus Helicosphaera serta genus Calcidiscus merupakan indikasi daerah upwelling yang juga dipengaruhi oleh pertemuan arus hangat dan arus dingin. 


\section{UCAPAN TERIMA KASIH}

Penulis berterima kasih kepada seluruh anggota Tim Cekungan Sawu 2014 yang telah membantu dalam pengambilan data, Prof. Dr. Ir. Roebiyanto Kapid yang telah membantu dalam pengambilan foto nanofosil gampingan, supervisi identifikasi nanofosil gampingan, dan semua pihak yang telah memberikan saran sehingga menjadikan tulisan ini lebih baik.

\section{DAFTAR PUSTAKA}

Audley-Charles, M.G., 2011. Tectonic postcollision processes in Timor, 241-266 dalam Hall, R., Cottam, M. A., dan Wilson, M. E. J., ed., The SE Asian gateway: History and tectonics of the Australia-Asia collision, 382 hal., The Geological Society 355, LondonUK.

Cai, Y.F., Li, X., Pan, Y.G., dan Hu, X.M., 2008. The colour causing mechanism of $\mathrm{Mn}^{2+}$ and $\mathrm{Fe}^{3+}$ : Evidence from the Italian Cretaceous pelagic red limestones. Acta Geologica Sinica, 82(1), 133-138.

Cai, Y.F., Li, X., Hu, X.M., Chen, X.M., dan Pan, Y. G., 2009. Paleoclimatic approach to the origin of the colouring of Turonian pelagic limestones from the Vispi Quarry section (Cretaceous, central Italy). Cretaceous Research, 30(5), 1205-1216. DOI: 10.1016/j.cretres.2009.06.002.

Cai, Y., Hu, X., Li, X., dan Pan, Y., 2012. Origin of the red colour in a red limestone from the Vispi Quarry section (central Italy): A high-resolution transmission electron microscopy analysis. Cretaceous Research, 28, 97-102. DOI: doi.org/10.1016/j.cretres.2011.11.016.

Chira, C. Dan Malacu, A., 2008. Biodiversity and paleoecology of the Miocene calcareous nannoplankton from Sibiu area (Transylvania, Romania). Acta Palaeontologica Romaniae, 6, 17-28.

De Wever, P., O’Dogherty, L., dan Gorican, S., 2014. Monsoon as a cause of radiolarite in the Tethyan realm. Geoscience, 346, 287297. DOI: $10.1016 /$ j.crte.2014.10.001.

Hu, X.M., Jansa, L., Wang, C.S., Sarti, M., Bak, K., Wagreich, M., Michalik, J., dan Sotak, J., 2005. Upper cretaceous oceanic red beds (CORBs) in the Tethys: Occurrences, lithofacies, age, and environments. Cretaceous Research, 26(1), 3-20. DOI: doi.org/10.1016/j.cretres.2004.11.011.
Hu, X., Hu, X., Wagreich, M., dan Yilmaz, I.O., 2012. Marine rapid environmental/climatic change in the cretaceous greenhouse world. Cretaceous Research, 38, 40-51. DOI: doi.org/10.1016/j.cretres.2012.04.012.

Ines, G., 2017 Sarmatian calcareous nannofossil assemblages in the SW Paratethyan marginal marine environments: implications for palaeoceanography and the palaeoclimate. Progress in Oceanography, doi: http://dx.doi.org/10.1016/j.pocean.2017.05.0 11

Martini, E., 1971. Standard Tertiary and Quaternary calcareous nannoplankton zonation. Proceedings, 2nd Planktonic Conference, Roma, 739-784.

Perch-Nielsen, K., 1985. Cenozoic Calcareous nannofossils, dalam H. Bolli, J.B. Saunders and K. Perch-Nielsen, ed., Plankton stratigraphy, 427-554 hal., Cambridge Earth Sci. Ser., London-UK.

Rahman, A. dan Roth, P.H., 1990. Late Neogene paleoceanography and paleoclimatology of the Gulf of Aden region based on calcareous nannofossils. Paleoceanography, 5, 91-107. DOI: doi.org/10.1029/PA005i001p00091.

Rosidi H.M.D., Tjokrosapoetro, S., dan Gafoer, S., 1979. Peta Geologi Lembar Kupang, Timor. Pusat Penelitian dan Pengembangan Geologi, Bandung.

Rosidi H.M.D., Tjokrosapoetro, S., dan Gafoer, S., 1996. Peta Geologi Lembar KupangAtambua, Timor. Pusat Penelitian dan Pengembangan Geologi, Bandung.

Roosmawati, N. dan Harris, R., 2009. Long-term surface uplift history of the active Banda arccontinent collision: Depth and age analysis of foraminifera from Rote and Savu Islands, Indonesia. Tectonophysics, 479, 95-110. DOI: doi.org/10.1016/j.tecto.2009.04.009.

Sawyer. R. K., Sani, K., dan Brown, S., 1993. The stratigraphy and sedimentology of West Timor, Indonesia. Proceedings of Indonesian Petroleum Association 22nd Annual Convention, Jakarta, Indonesia, 533-574.

Silva, A., Palma, S., dan Moita, M.T., 2008. Coccolithophores in the upwelling waters of Portugal: Four years of weekly distribution in Lisbon bay. Continental Shelf Research, 28, 2601-2613. DOI: 10.1016/j.csr.2008.07.009.

Villeneuve, M., Bellon, H., Martini, R., Harsolumakso, A., Cornée, J. J., 2013. West Timor: a key for the eastern Indonesian 
geodynamic evolution. Bull. Soc. géol. France, 184(6), 569-354.

Wang, C., Hu, X., Huang, Y., Scott, R., dan Wagreich, M., 2009. Cretaceous oceanic red beds (CORB): A window on global oceanic/climatic change, 13-33 dalam $\mathrm{Hu}$,
X., Wang, C., Scott, R.W., Wagreich, M., dan Jansa, L., (Ed.), Cretaceous oceanic red beds: Stratigraphy, composition, origins and paleoceanographicl paleoclimatic significance, 276 hal., SEPM Special Publication 91, Tulsa, OK-USA. 